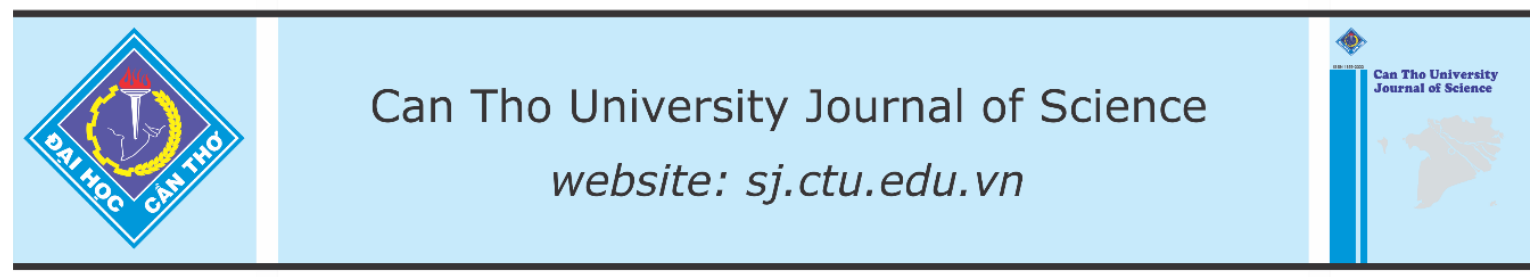

DOI: 10.22144/ctu.jen.2021.006

\title{
ELT pedagogical reforms: EFL high-school teachers' perceptions and responses
}

\author{
Le Thanh Thao ${ }^{1}$ and Le Xuan Mai ${ }^{2 *}$ \\ ${ }^{1}$ Master student of Can Tho University, Vietnam \\ ${ }^{2}$ School of Foreign Languages, Can Tho University, Vietnam \\ *Correspondence: Le Xuan Mai (email: lxmai@ctu.edu.vn)
}

\section{Article info.}

Received 01 May 2020

Revised 05 Jul 2020

Accepted 31 Mar 2021

\section{Keywords}

Educational change, EFL high-school teachers, ELT pedagogical reforms, perceptions, understanding, practices in response

\begin{abstract}
Educational change, particularly English language teaching (ELT) pedagogical reforms, has received much attention from language researchers in the era of globalization and internationalization. Despite the recognition of problems in implementation, ELT pedagogical reforms have been widely introduced and adopted in schools all over the world, particularly in Vietnam. What English teachers' overall perceptions, understanding, and practices are, and what influential factors on response to ELT pedagogical reforms are, the major foci in this study. The data were collected from 102 teachers of English as a Foreign Language (EFL) in different high-schools (grades 10, 11 and 12) in the Mekong Delta. The results from the questionnaire and interview revealed that the teachers highly perceived ELT pedagogical reforms. Moreover, the results also showed that the teachers well understood the values of ELT pedagogical reforms. However, the findings also showed that the teacher's practices of ELT pedagogical reforms were above average and that their practices did not match with their understanding of the values of ELT pedagogical reforms. Besides that, from the findings, the EFL high-school teachers were relative strongly influenced, both the internal and external factors; the main influential factors are students' learning outcomes after implementing ELT pedagogical reforms, teachers' attitudes towards the adoption of these reforms, and teachers' self-efficacy on their teaching. Moreover, the study contributed an interesting finding to the literature that teaching and learning culture is a factor that influenced teachers' responses. Based on these findings, implications were made for enhancing teachers' teaching practices in response to ELT pedagogical reforms.
\end{abstract}

\section{INTRODUCTION}

In the era of globalization, the governments of many countries are focusing on educational reforms, especially English language teaching pedagogical reforms (ELT pedagogical reforms). In Vietnam, to enhance positive results in teaching and learning English, Decision No. 1400/QĐ-TTg (Deputy Prime Minister, 2008) and Decision No. 2658/QĐ-
BGDĐT (MOET, 2018) are promulgated. However, the results of English in the annual national graduation examination of high-school students in Vietnam are still not satisfactory (Nguyen, 2018). The reasons for this subjective judgment are due to far-off and unrealistic goals (Le \& Nguyen, 2018) because these goals do not match with the proficiency and willingness to change of high-school teachers of 
English as a Foreign Language (EFL). Actually, the person directly involved in the project is none other than the EFL high-school teachers. Any ELT changes or reforms in education and pedagogy cannot be effective without EFL high-school teachers' participation. Therefore, their opinions are important to see whether these reforms are appropriate or not, realistic or unrealistic. Although there are many studies on educational change and pedagogical reforms in countries around the world, including Vietnam (i.e. Harvey \& Broyles, 2010; Ibrahim, AlKaabi, \& El-Zaatari, 2013; Nguyen \& Burns, 2017), there is still little research to find out how EFL highschool teachers perceive ELT pedagogical reforms, especially in the Vietnamese context; and, how Vietnamese EFL high-school teachers respond to these reforms in practice and the reasons why they resist or accept these reforms needs to be well-explained. Due to the reasons presented, this study is aimed to figure out (1) EFL high-school teachers' overall perceptions and their understanding of ELT pedagogical reforms, (2) their practice in response to these reforms, and (3) the factors that influence their responses to ELT pedagogical reforms.

\section{LITERATURE REVIEW}

\subsection{Definitions of ELT pedagogical reforms}

"Pedagogy", playing a crucial role in education, has been well-defined in the literature. Firstly, Ozuah (2016) defined pedagogy literally as "the art and science of teaching children" (p.83). Additionally, in Cambridge dictionary, pedagogy means "the study of the methods and activities of teaching". According to a definition provided by Watkins and Mortimore (1999), the term "pedagogy" is "any conscious activity by one person designed to enhance learning in another" (p.17). The characteristics of pedagogy are topic orientation, the uses of lecture and other cognitive techniques, the uses of reinforcement to encourage students' learning, and the important role of the teachers (Marshak, 1983). While a variety of definitions of the term "pedagogy" have been suggested, pedagogy is used solely when referring to the art of teaching that includes teaching activities designed to develop students' learning in this study. As a result, the term "ELT pedagogical reform" means a process of transforming pedagogy related to ELT from the original form to a new form to enhance EFL students' learning. The ELT pedagogical reforms are characterized by the same elements with pedagogy but they focus more on ELT. Peterson et al. (1994), cited in Knapp (1997), stated that reforming pedagogy is considered as a chance to learn. It means that pedagogical reforms aim to do a process of professional development and continue to learn new things.

\subsection{Needs for ELT pedagogical reforms}

Burner (2018) pointed out the three needs for ELT pedagogical reforms, namely globalization, technological development, and the development of research into teaching and learning approaches.

- Globalization: When globalization increases, it leads to a diverse population with many different cultures and different languages. Educational change or ELT pedagogical reforms are aimed to provide knowledge for students to be able to learn in a multilingual classroom.

- Technological development: Advancements in technology create new ways of teaching and learning, new types of knowledge, new jobs, and an unpredictable future. Further, it requires an educational change to catch up the technological development.

- The development of research into teaching and learning approaches: The number of researches related to the effectiveness of teaching and learning approaches provided valuable information about which approach is suitable for teaching and learning in different contexts. Therefore, more research is conducted to provide information on teaching approaches, the more effective teaching can be.

\subsection{Types of ELT pedagogical reforms in Vietnam}

Based on the Decisions No. 2658/QĐ-BGDĐT (Ministry of Education and Training of Vietnam MOET) and No. 2540/SGDĐT-GDTrH (Department of Education and Training - DOET), 15 specific tasks to reform English pedagogy, considered as the types of ELT pedagogical reforms in this study, are (1) establishing English communities, (2) doing ELT action research, (3) focusing on language use, (4) using open-ended questions or referential questions to enhance students' critical thinking, (5) teaching grammar in context, (6) integrating skills in a lesson, (7) using technology in teaching, (8) teaching vocabulary in phrases and collocations, (9) using mind-map, (10) conducting subject-based studies, (11) adapting teaching materials, (12) participating extra-curricular activities and English speaking clubs, (13) designing English proficiency tests based on the Vietnamese Standardized Test of 
English (VSTEP) framework, (14) implementing oral tests, and (15) doing on-going assessment.

\subsection{Teachers' response to ELT pedagogical reforms}

The two ways of teachers' response to ELT pedagogical reforms are resistance and acceptance.

\subsubsection{Teachers' resistance to ELT pedagogical reforms}

Resistance to change is a kind of mentality that people resist unusual things (Gravenhorst, 2003, cited in Ali El Zaatar, 2011). Ali El Zaatar (2011) defined term resistance to change as a lack of interest and collaboration to make a change, and people who resist change prefer to keep the status quo. Fullan and Ballew (2004) described a change as a double-edged sword because the change cannot occur in stagnant societies where people are not interested in changing.

\subsubsection{Teachers' acceptance of ELT pedagogical reforms}

According to Ali El Zaatar (2011), the differences in school culture create different responses to change. When change occurs, some teachers resist changing because of several causes. However, change can be accepted and supported. Change acceptance plays the opposite pole of change resistance (Coetsee, 1999). Mohamad et al. (2019) called resistance and acceptance as the two-polar opposite of change. Other than change resistance, there is little research on change acceptance. While the topic resistance to change has been studied through the years, acceptance to change cannot find a concrete definition (Mohamad et al., 2019).

\subsection{The influential factors of EFL high-school teachers' response to ELT pedagogical reforms}

Based on the foundations of Ali El Zaatar (2011) and Thieman (2000), the researcher created a more detailed model of EFL teachers' responses to ELT pedagogical reforms influential factors, which are divided into two groups of the internal factors and the external factors. First, the internal factors include prior learning and teaching experiences, teaching beliefs, teachers' attitudes, teachers' confidence in learning abilities, stress, teachers' participation in educational reforms, teachers' sense of empowerment, and teachers' self-efficacy. Second, the external factors consist of previous educational policies, professional communities and colleagues, institution managers' leadership, students' learning outcomes, and time for implementing. Figure $1 \mathrm{de}-$ scribes the overview of influential factors.

Influential factors

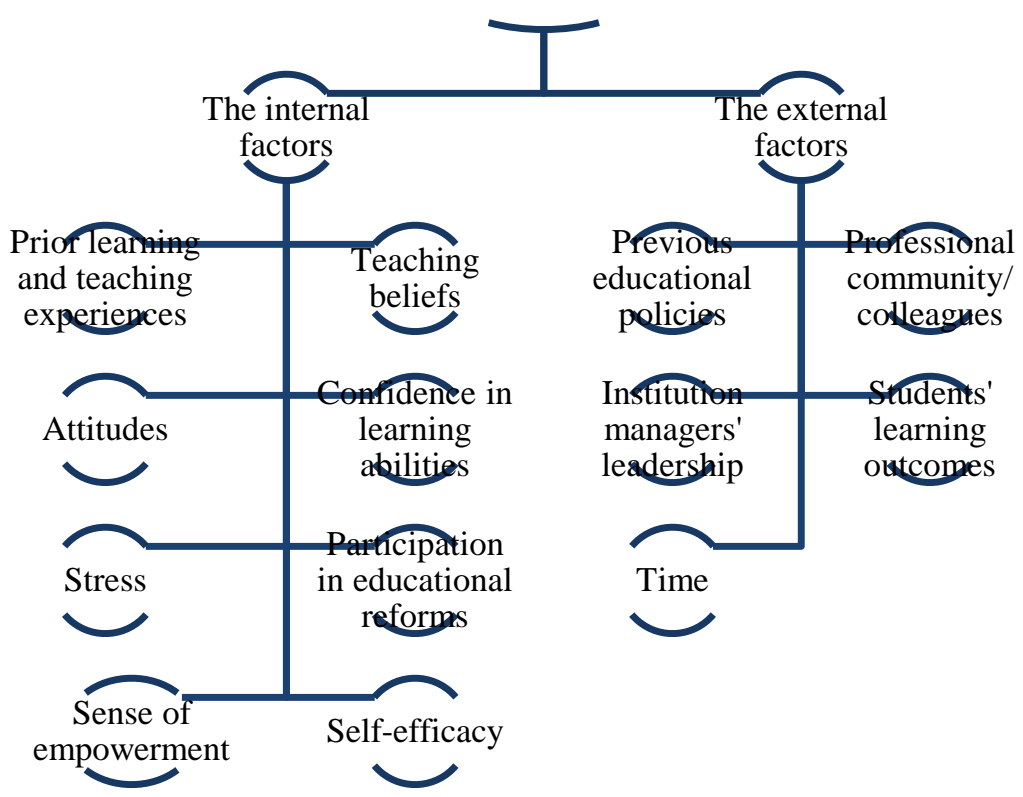

Figure 1. The influential factors of EFL teachers' practice in response to ELT pedagogical reforms 


\section{METHODOLOGY}

This study was guided by three research questions, in which the research question 1 was divided into two sub-questions.

1. What are EFL high-school teachers' perceptions of ELT pedagogical reforms?

1a. What are their overall perceptions of ELT pedagogical reforms?

1b. What is their understanding of ELT pedagogical reforms?

2. What is EFL high-school teachers' practice in response to ELT pedagogical reforms?

3. What factors influence EFL high-school teachers' response to ELT pedagogical reforms?

To identify EFL high-school teachers' overall perceptions, understanding, practice in response, and the factors that influence their responses to ELT pedagogical reforms, this study was conducted quantitatively, followed by qualitatively, i.e. a mixed-method approach. There are strengths in the mixed-methods approach because different methods can support each other to draw a complete research picture (Morrison, 2007). While quantitative data provides information on a large sample and yields results on frequency and magnitude of trends, qualitative data offers insightful perspectives on the research topic and provides details of the situation. The two methods when combined together allow the research to assess both outcomes and process of the social phenomenon.

The questionnaire consisted of 34 items, representing three clusters, including teachers' understanding, practice in response, and the factors that influence their responses to ELT pedagogical reforms. The Likert-scale, ranging from strongly disagree (1) to strongly agree (5) and from never (1) to always (5), was used. Besides that, in the questionnaire, there was option "Others", which was used to obtain more ideas from the teachers if the items did not cover enough issues. Furthermore, semi-structured interviews were conducted to gain more insights into teachers' thoughts on the topic.

The questionnaire in format of Google Form was sent via email to collect data from 102 EFL highschool teachers, who are working at different high schools in seven provinces and cities in the Mekong Delta in Vietnam. Besides that, because of COVID19 pandemic, the interviews were conducted online by these platforms, Zalo, Zoom, and Skype.

\section{RESULTS}

The results of the questionnaire and the findings from the interviews were presented in this section.

\subsection{EFL high-school teachers' overall perceptions of ELT pedagogical reforms}

A descriptive statistics test was run on the mean score of teachers' overall perceptions and three clusters including understanding, practice, and influential factors. The results represented in Table 1 show that the mean score of teachers' overall perceptions $(\mathrm{M}=3.80)$ is relatively high. Therefore, to confirm that there was a significant difference between the mean score 3.80 and the test value 3.50 , the accepted score for a medium level of teachers' overall perceptions, a one-sample T-test was run. The results of this test showed that they were different $(\mathrm{p}<.05)$. It can be concluded that ELT pedagogical reforms were highly perceived by EFL high-school teachers in this study.

Besides that, among the three clusters, the mean score of teachers' understanding of ELT pedagogical reforms $(\mathrm{M}=4.28)$ is highest. Although the results of that of practice and the influential factors are not as that high, they are accepted as a high level of perceptions with the mean scores 3.68 and 3.74 respectively.

Table 1. EFL high-school teachers' overall perceptions $(\mathrm{N}=102)$

\begin{tabular}{lccccc}
\hline Variables & N & Min. & Max. & Mean & SD \\
\hline Understanding & 102 & 1.40 & 5.00 & 4.28 & .54 \\
\hline Practice & 102 & 1.87 & 4.80 & 3.68 & .50 \\
\hline The influential factors & 102 & 2.57 & 4.57 & 3.74 & .38 \\
\hline Total mean $=3.80(\mathrm{M}=3.80)$ & & & &
\end{tabular}

Furthermore, although they highly understood the values of ELT pedagogical reforms, their practice in response to ELT pedagogical reforms seemed to be not correspondent with. However, it could be explained that their practice in response was affected by the influential factors when the mean score of practice and that of the influential factors are not significantly different. 


\subsection{EFL high-school teachers' understanding of ELT pedagogical reforms}

A descriptive statistics test was run on the mean score of teachers' perceptions of their understanding, which consists of the first five items representing the definitions, the functions, and needs for ELT pedagogical reforms. The results of Table 2 show that the mean score of teachers' perceptions of understanding of ELT pedagogical reforms $(M=4.28)$ is high. A one-sample T-test was run to check whether this mean score was different from the test value 3.50 or not. The results supported the conclusion that EFL high-school teachers had a high understanding of ELT pedagogical reforms ( $p<.05)$.
Besides that, the mean score of teachers' perceptions of their understanding of the need for globalization ( $M=4.42)$ was the highest, followed by that of functions $(\mathrm{M}=4.34)$, need for technological development $(M=4.29)$, definitions $(M=4.21)$, and need for the development of research into teaching and learning approaches $(\mathrm{M}=4.16)$. It could be concluded that EFL high-school teachers understood ELT pedagogical reforms very well, especially their understanding of the need for globalization. In other words, teachers agreed that reforming ELT was a process of transforming the traditional teaching methods to the newer ones. Then, it was a chance to improve their teaching. Besides that, ELT pedagogical reforms occur to catch up with the globalization, technological development, and the development of research into teaching and learning approaches.

Table 2. EFL high-school teachers' understanding of ELT pedagogical reforms $(\mathrm{N}=102)$

\begin{tabular}{lrrrrr}
\hline Variables & $\mathbf{N}$ & Min. & Max. & Mean & SD \\
\hline Definitions & 102 & 2 & 5 & 4.21 & .72 \\
Functions & 102 & 1 & 5 & 4.34 & .72 \\
Need for globalization & 102 & 1 & 5 & 4.42 & .74 \\
Need for technological development & 102 & 1 & 5 & 4.29 & .74 \\
Need for the development of research into teaching and learning & 102 & 2 & 5 & 4.16 & .64 \\
approaches & & & &
\end{tabular}

Total mean $=4.28(\mathrm{M}=4.28)$

Additionally, the findings from the interviews made it understandable why teachers had that good knowledge of ELT pedagogical reforms. Firstly, the participants were active in receiving the information related to their works, such as reading magazines and newspapers, or looking for information on the Internet about ELT pedagogical reforms. Secondly, the Department or the Ministry of Education and Training of Vietnam also contributed to these results with their documentaries which provided amount of necessary information about ELT pedagogical reforms. It supported the idea that the dissemination of ELT pedagogical reforms in Vietnam would be good.

\subsection{Teachers' practices in response to ELT pedagogical reforms}

A descriptive statistics test was run to investigate the overall mean score of teachers' practice response and their response to each type of ELT pedagogical reforms. The results observed in Table 3 showed that the mean score of teachers' practice in response to ELT pedagogical reforms $(\mathrm{M}=3.68)$ was relatively high. A one-sample T-test was also run to see if this mean score and the test value 3.50 were different or not. The results showed that the p-value was lower than .05. Therefore, it could be concluded that EFL high-school teachers highly accepted ELT pedagogical reforms through their practices.

Besides that, the mean score of adapting teaching material $(M=4.24)$ was the highest, followed by integrating skills in a lesson $(\mathrm{M}=4.14)$, teaching grammar in context $(\mathrm{M}=4.10)$, doing on-going assessment $(\mathrm{M}=4.08)$, using technology in teaching $(\mathrm{M}=3.94)$, using open-ended questions or referential questions to enhance students' critical thinking $(\mathrm{M}=3.94)$, focusing on language use $(\mathrm{M}=3.85)$, teaching vocabulary in phrases and collocations $(\mathrm{M}$ $=3.79)$, implementing oral tests $(\mathrm{M}=3.79)$, doing ELT action research $(\mathrm{M}=3.54)$, conducting subjectbased studies $(\mathrm{M}=3.52)$, participating in extra-curricular activities and English speaking club $(\mathrm{M}=$ 3.50), using mind-map $(\mathrm{M}=3.10)$, establishing English communities $(M=2.96)$, and designing proficiency tests based on the VSTEP framework ( $\mathrm{M}=$ 2.75). Moreover, ten-year English textbooks was mentioned in the "Others" item.

It can be concluded that teachers relatively accepted ELT pedagogical reforms. Besides that, adapting teaching material, integrating skills in a lesson, and teaching grammar in context were accepted by most 
of the teachers. In contrast, using mind-map, establishing English communities, and designing proficiency tests based on the VSTEP framework were resisted by most of the teachers.

Table 3. EFL high-school teachers' response to each type of ELT pedagogical reforms $(N=102)$

\begin{tabular}{|c|c|c|c|c|c|c|c|}
\hline Items & Types & $\begin{array}{r}\text { Mean } \\
\text { score }\end{array}$ & $\begin{array}{r}\text { Never } \\
(\%) \\
\end{array}$ & $\begin{array}{r}\text { Rarely } \\
(\%) \\
\end{array}$ & $\begin{array}{r}\text { Sometimes } \\
(\%) \\
\end{array}$ & $\begin{array}{r}\text { Often } \\
(\%) \\
\end{array}$ & $\begin{array}{r}\text { Always } \\
(\%) \\
\end{array}$ \\
\hline 2.1 & Establishing English communities & 2.96 & 9.8 & 21.6 & 35.3 & 29.4 & 3.9 \\
\hline 2.2 & Doing ELT action research & 3.54 & 3.9 & 5.9 & 35.3 & 42.2 & 12.7 \\
\hline 2.3 & Focusing on language use & 3.85 & 2.0 & 2.0 & 25.5 & 50.0 & 20.6 \\
\hline 2.4 & $\begin{array}{l}\text { Using open-ended questions or refer- } \\
\text { ential questions to enhance students' } \\
\text { critical thinking }\end{array}$ & 3.94 & 0 & 3.9 & 21.6 & 51.0 & 23.5 \\
\hline 2.5 & Teaching grammar in context & 4.10 & 1.0 & 0 & 16.7 & 52.9 & 29.4 \\
\hline 2.6 & Integrating skills in a lesson & 4.14 & 1.0 & 1.0 & 10.8 & 57.8 & 29.4 \\
\hline 2.7 & Using technology in teaching & 3.94 & 0 & 2.0 & 27.5 & 45.1 & 25.5 \\
\hline 2.8 & $\begin{array}{l}\text { Teaching vocabulary in phrases and } \\
\text { collocations }\end{array}$ & 3.79 & 1.0 & 3.9 & 30.4 & 44.1 & 20.6 \\
\hline 2.9 & Using mind-map & 3.10 & 2.9 & 17.6 & 51.0 & 23.5 & 4.9 \\
\hline 2.10 & Conducting subject-based studies & 3.52 & 2.9 & 7.8 & 35.3 & 42.2 & 11.8 \\
\hline 2.11 & Adapting teaching material & 4.24 & 0 & 0 & 12.7 & 51.0 & 36.3 \\
\hline 2.12 & $\begin{array}{l}\text { Participating in extra-curricular activ- } \\
\text { ities and English speaking club }\end{array}$ & 3.50 & 2.9 & 14.7 & 29.4 & 35.3 & 17.6 \\
\hline 2.13 & $\begin{array}{l}\text { Designing English proficiency tests } \\
\text { based on the VSTEP framework }\end{array}$ & 2.75 & 13.7 & 24.5 & 39.2 & 18.6 & 3.9 \\
\hline 2.14 & Implementing oral tests & 3.79 & 0 & 7.8 & 23.5 & 50.0 & 18.6 \\
\hline 2.15 & Doing on-going assessment & 4.08 & 2.0 & 1.0 & 11.8 & 57.8 & 27.5 \\
\hline
\end{tabular}

Total mean $=3.68(\mathrm{M}=3.68)$

The qualitative data showed that in terms of the most supported types, all teachers participating in the interviews confirmed that they usually adopt these types of ELT pedagogical reforms in their teaching. Several reasons for adopting specific types of ELT pedagogical reforms, especially adapting teaching materials, were mentioned to explain for the teachers' acceptance. The reasons refer to making their students less bored, reducing the difficulties of lessons to be more appropriate to their students' levels, and bringing many benefits. In contrast, although each teacher differently responded to the types they resisted, specifically designing tests based on VSTEP framework, they did not adopt these types much due to the unsuitability for their teaching and lack of requirements from the superiors to do these types.

\subsection{The factors influencing EFL high-school} teachers' response to ELT pedagogical reforms

A descriptive statistics test was run on the overall mean score of influential factors and that of two types of the influential factors, namely as the internal factors and the external factors. The results from the questionnaire observed in Table 4 showed that the mean score of the influential factors of EFL high-school teachers' response to ELT pedagogical reforms $(\mathrm{M}=3.74)$ was relatively high. A one-sample T-test was used to investigate the differences between the mean score and the test value 3.50. The results were that they were different from each other $(\mathrm{p}<.05)$. It supported the conclusion that EFL highschool teachers were relatively affected.

Table 4. The influential factors of EFL high-school teachers' response $(N=102)$

\begin{tabular}{|c|c|c|c|c|c|}
\hline Variable & $\mathbf{N}$ & Min. & Max. & Mean & SD \\
\hline The internal factors & 102 & 2.44 & 4.67 & 3.74 & .41 \\
\hline The external factors & 102 & 2.20 & 5.00 & 3.77 & .42 \\
\hline
\end{tabular}


Besides that, the mean score of the external factor $(\mathrm{M}=3.77)$ was higher than that of the internal factors $(M=3.74)$. Additionally, although the results showed that the external factors affected EFL highschool teachers' responses more than the internal factors did, it was not significantly different.

Furthermore, a Descriptive Statistics Test was run on the mean score of each factor of ELT pedagogical reforms. The results presented in Table 5 showed that the mean score of students' learning outcomes $(\mathrm{M}=4.53)$ was highest, followed by that of self-efficacy $(M=4.22)$, attitudes $(M=4.00)$, sense of empowerment $(\mathrm{M}=3.82)$, confidence in learning and teaching abilities $(\mathrm{M}=3.80)$, institution managers' leadership $(\mathrm{M}=3.79)$, time $(\mathrm{M}=3.74)$, participation in educational reforms $(\mathrm{M}=3.72)$, teaching beliefs $(\mathrm{M}=3.66)$, stress $(\mathrm{M}=3.59)$, previous educational policies $(\mathrm{M}=3.39)$, professional communities/colleagues $(\mathrm{M}=3.34)$, and prior learning and teaching experiences $(\mathrm{M}=2.81)$. It can be concluded that teachers' responses to ELT pedagogical reforms were affected by students' learning outcomes most. In contrast, they were not significantly affected by their prior teaching and learning experiences.

In the "Others" item, "students' levels", "school's facilities", and "students' attitudes" were provided.

Table 5. Each factor of EFL high-school teachers' response $(N=102)$

\begin{tabular}{lrrrrr}
\hline Factors & N & Min. & Max. & Mean & SD \\
\hline Prior learning and teaching experiences & 102 & 1 & 4 & 2.81 & .83 \\
Teaching beliefs & 102 & 2 & 5 & 3.66 & .81 \\
Attitudes & 102 & 1.5 & 5 & 4.00 & .65 \\
Confidence in learning and teaching abilities & 102 & 1 & 5 & 3.80 & .94 \\
Stress & 102 & 1 & 5 & 3.59 & 1.00 \\
Participation in educational reforms & 102 & 2 & 5 & 3.72 & .74 \\
Sense of empowerment & 102 & 2 & 5 & 3.82 & .75 \\
Self-efficacy & 102 & 2 & 5 & 4.22 & .64 \\
Previous educational policies & 102 & 1 & 5 & 3.39 & 1.10 \\
Professional community/colleagues & 102 & 1 & 5 & 3.34 & .96 \\
Institution managers' leadership & 102 & 1 & 5 & 3.79 & .91 \\
Students' learning outcomes & 102 & 2 & 5 & 4.53 & .70 \\
\hline Time & 102 & 1 & 5 & 3.74 & .94 \\
\hline
\end{tabular}

Additionally, the qualitative data from the interviews showed that EFL high-school teachers' responses to ELT pedagogical reforms were strongly affected by students' learning outcomes, institution managers' leadership, previous educational policies, and their attitudes. Moreover, students' level, school's facilities, and students' attitudes were confirmed to be the influential factors of EFL highschool teachers' response to ELT pedagogical reforms.

An extremely interesting finding, Vietnamese learning culture as an influential factor, was found in this study that has not been mentioned by any previous research. Teachers thought that a long time ago, Vietnamese students have been taught that they have to keep silent to listen to the teachers in an orderly manner. Therefore, when ELT pedagogical reforms for enhancing students' communicative competence occur, it is difficult to change students' habits. As a result, teachers' resistance to change is unavoidable.

\section{DISCUSSIONS}

For EFL high-school teachers' overall perceptions and understanding of ELT pedagogical reforms, the findings of this study related to teachers' overall perceptions of ELT pedagogical reforms showed that teachers are well aware of the value of these reforms. Particularly, teachers had a good understanding of the definition, the function, and the needs for ELT pedagogical reforms. It is the reason why teachers tended to accept these reforms, particularly, and the change in general. These results were consistent with that of Nisbet and Collins (1978), which showed a high level of stated acceptance because teachers recognized the values of the change. Besides that, teachers' good understanding of ELT pedagogical reforms is not only from their selfstudy of ELT pedagogical reforms but also comes from the dissemination of the Department of the Ministry of Education. The dissemination may make a huge impact on changing teachers' attitudes, beliefs, and knowledge of ELT pedagogical reforms 
to enhance teachers' willingness to adopt these reforms in their teaching. This interpretation was supported by the findings of Huberman (1981).

Regarding teachers' response to ELT pedagogical reforms, EFL high-school teachers accepted the change in this study. It was consistent with the findings of many previous studies (Emo, 2010; Ibrahim, Al-Kaabi, \& El-Zaatari, 2013; Nisbet \& Collins, 1978).

In terms of the factors that influence teachers' response to ELT pedagogical reforms, this study showed that teachers would continue to adopt the reforms if the implementation brought the improvement in their students' learning. It is similar to the findings of Emo (2010), which showed that teachers accept change because of the expectation that the change can improve their students' learning. The following result of this study showed that prior teaching and learning experiences play the role of a supportive factor for evaluating ELT pedagogical reforms before teachers adopt these reforms, which lead to teachers' resistance to change. This result supported the findings of Nisbet and Collins (1978), which considered trusting in the old teaching methods or lack of trusting in the values of change as a preventive factor of teachers' acceptance to change. Besides that, Brickell (1964), cited in Koksal (2013), pointed out eight causes of teachers' resistance and one of them is teachers' confidence in their own teaching methods.

Finally, this study added four influential factors that were not mentioned in the literature. They referred students' levels, students' attitudes, school's facilities, and Vietnamese learning culture.

\section{CONCLUSIONS}

Firstly, the study showed that the dissemination brought positive results in enhancing teachers' perceptions, understanding, and their practice in response to ELT pedagogical reforms as well. Therefore, it should be continued effectively as before. Moreover, the Ministry of Education and Training of Vietnam should organize more training activities to raise teachers' awareness and understanding of pedagogical reforms.

Secondly, although EFL high-school teachers well understood the values of ELT pedagogical reforms, they just sometimes adopted these reforms in their practice. Teachers reported that they were influenced by many influential factors, some hindered their responses to ELT pedagogical reforms and some encouraged them to adopt these reforms. For the influential factors, hindering teachers' response to ELT pedagogical reforms, the administrators should limit their influence on teachers as much as possible. In terms of encouraging factors, the administrators need to be aware of their strengths and maximize them to enhance teachers' willingness to change.

Finally, EFL high-school teachers, themselves, should be constantly developing their learning and teaching abilities and being active in collecting information about different types of ELT pedagogical reforms. This helps teachers improve their understanding and the effectiveness of their adoption of each type of ELT pedagogical reforms. Besides that, this study also suggests that before implementing any type of ELT pedagogical reforms, it should be carefully evaluated to see if it works in Vietnam or not. This will greatly reduce the loss of money, effort, and time.

\section{REFERENCES}

Ali El Zaatar, W. M. (2011). Resistance to Educational Change from the Perspective of Teachers in Al Ain Educational Zone in UAE. Master thesis. United Arab Emirates University. UAE.

Burner, T. (2018). Why is educational change so difficult and how can we make it more effective? 1, 122-134.

Coetsee, L. S. (1999). From resistance to commitment. Public Administration Quarterly. 23, 204- 222.

Department of Education and Training of Cantho City. (2019). Decision No. 2540/SGDĐT-GDTrH, dated on October 7, 2019, Guidelines for Teaching Foreign Languages at secondary schools and high schools, academic year 2019-2020 (L.X.Mai, Trans.).

Deputy Prime Minister. (2008). Decision No. 1400/QĐTTg, dated on September 30, 2008, Plan for Foreign Languages Teaching and Learning in the National Educational System, period 2008-2020 (L.X.Mai, Trans.). Accessed on June 24, 2020. Available from: http://vanban.chinhphu.vn/portal/page/portal/chinhphu/hethongvan-

ban?class_id=1\&_page=2\&mode=detail \&document_id=78437

Emo, W. (2010). Teachers Who Initiate Curriculum Innovations: Motivations and Benefits. Doctoral dissertation, University of York.

Fullan, M., \& Ballew, A. (2004). Leading in a culture of change: Personal action guide and workbook. San Francisco: Jossey-Bass.

Harvey, T. R., \& Broyles, E. A. (2010). Resistance to change: A guide to harnessing its positive power. R\&L Education.

Huberman, M. (1981). North Plains: Case Study. MA. The NETWORK. Inc. Andover. 
Ibrahim, A., Al-Kaabi, A., \& El-Zaatari, W. (2013). Teacher resistance to educational change in the United Arab Emirates. International Journal of Research Studies in Education, 2(3), 25-36.

Knapp, M. S. (1997). Between systemic reforms and the mathematics and science classroom: The dynamics of innovation, implementation, and professional learning. Review of Educational Research, 67(2), 227-266.

Koksal, H. (2013). Reducing Teacher Resistance to Change and Innovations. Prepared address, Kingston University, London, England.

Le, V. C., \& Nguyen, T. N. (2018). What can the National Foreign Language Project 2020 learn from Asian experience? VNU Journal of Foreign Studies, 33(4).

Marshak, R. J. (1983). What's between pedagogy and andragogy? Training \& Development Journal, 37(10), 80-81.

MOET, Ministry of Education and Training of Vietnam. (2018). Decision No. 2658/QĐ-BGDĐT, dated on July 23, 2018, Plan for Foreign Languages Teaching and Learning in the National Educational System, period 2017-2021 (L.X.Mai, Trans.). Accessed on June 24, 2020. Available from https://thuvienphapluat.vn/van-ban/giao-duc/Quyet-dinh-2658-QDBGDDT-2018-De-an-day-va-hoc-ngoai-ngu-tronghe-thong-giao-duc-quoc-dan-396325.aspx.

Mohamad, S. J. A. N. S., Hassan, R., \& Hamid, N. A. (2019). Modelling a Change Acceptance Framework on School Education Reform. Revista Publicando, 6(19), 79-99.
Morrison, M. (2007). What do we mean by Educational Research? In: R.J. Briggs, and M. Coleman (Eds.), Research Methods in Educational Leadership and Management. 2nd Ed. Los Angeles, Sage Publications.

Nguyen, H. T. M., \& Burns, A. (2017). Teacher Language Proficiency and Reform of English Language Education in Vietnam, 2008-2020. Phnom Penh, 19.

Nguyen, T. M. T. (2018). EFL high school teachers' expectations and experiences of professional development: A case in Soc Trang province. Master thesis. Cantho University. Cantho City. Vietnam.

Nisbet, R. I., \& Collins, J. M. (1978). Barriers and Resistance to Innovation. Australian Journal of Teacher Education, 3(1), 2-29.

Ozuah, P. O. (2016). First, there was pedagogy and then came andragogy. Einstein journal of Biology and Medicine, 21(2), 83-87.

Thieman, G. Y. (2000). Factors influencing middle school teachers to change classroom practice in response to standards-based reform, p.63, 66.

Watkins, C., \& Mortimore, P. (1999). Pedagogy: What do we know. In: Understanding pedagogy and its impact on learning. SAGE. 1-19. 